\title{
Generation of dual specific bivalent BiTEs (dbBlspecific T-cell engaging antibodies) for cellular immunotherapy
}

\author{
Maciej Kujawski ${ }^{1 \dagger}$, Lin $\mathrm{Li}^{1 \dagger}$, Supriyo Bhattacharya ${ }^{2 \dagger}$, Patty Wong ${ }^{1}$, Wen-Hui Lee ${ }^{1}$, Lindsay Williams ${ }^{1}$, Harry Li ${ }^{1}$, \\ Junie Chea $^{3}$, Kofi Poku ${ }^{3}$, Nicole Bowles ${ }^{3}$, Nagarajan Vaidehi ${ }^{2}$, Paul Yazaki ${ }^{1}$ and John E. Shively ${ }^{1 *}$ (D
}

\begin{abstract}
Background: Bispecific T-cell engaging antibodies (BiTES), comprising dual anti-CD3 and anti-tumor antigen scFv fragments, are important therapeutic agents for the treatment of cancer. The dual scFv construct for BiTES requires proper protein folding while their small molecular size leads to rapid kidney clearance.

Methods: An intact (150 kDa) anti-tumor antigen antibody to CEA was joined in high yield (ca. 30\%) to intact (150 $\mathrm{kDa}$ ) anti-murine and anti-human CD3 antibodies using hinge region specific Click chemistry to form dual-specific, bivalent BiTES (dbBiTES, $300 \mathrm{kDa}$ ). dbBiTEs were tested in vitro by EM, flow cytometry and cell cytoxicity and in vivo by PET tumor imaging and redirected T-cell therapy.

Results: The interlocked hinge regions are compatible with a structural model that fits the electron micrographs of $300 \mathrm{kDa}$ particles. Compared to intact anti-CEA antibody, dbBiTES exhibit high in vitro cytotoxicity, high in vivo tumor targeting as demonstrated by PET imaging, and redirected dbBiTE coated T-cells (1 microgram/10 million cells) that kill CEA ${ }^{+}$target cells in vivo in CEA transgenic mice.
\end{abstract}

Conclusion: dbBiTE redirected T-cell therapy is a promising, efficient approach for targeting and killing cancer cells.

Keywords: BiTE, Bispecific antibody, T-cell therapy, CEA

\section{Background}

The concept of directing T-cells to tumors with bispecific antibodies that incorporate an anti-CD3 antibody and an anti-tumor antigen antibody into a single molecule was first explored 25 years ago when recombinant DNA technologies made the genetic engineering of bispecific antibodies possible [1]. Today the most widely used BiTE (Bispecific T-cell Engaging antibodies) constructs join two single chain Fv fragments together with a linker to form a 50kda protein. Examples of tumor target antigens include CD19, EpCAM, Her2/neu, EGFR, CEA, and more $[1,2]$. The BiTE anti-CD19/anti-CD3 (Blinatumomab) has had remarkable success in the treatment of several B-cell malignancies, suggesting that directing T-cell (and other

\footnotetext{
* Correspondence: jshively@coh.org

${ }^{\dagger}$ Maciej Kujawski, Lin Li and Supriyo Bhattacharya contributed equally to this work.

${ }^{1}$ Department of Molecular Imaging and Therapy, Beckman Research Institute City of Hope, Duarte, CA 91010, USA

Full list of author information is available at the end of the article
}

effector cells) to tumors by a bispecific antibody approach can be effective even against solid tumors [3]. Possible limitations of the therapy include the small molecular size that requires constant infusion of rather large amounts of BiTEs, the poly-activation of endogenous TCRs may lead to off target toxicity, and the lack of an engagement of a co-stimulus such as CD28 on the T-cell may limit effective tumor killing.

An alternate approach pioneered by Lum and associates [4-8] utilized heterobifunctional chemical cross-linking agents on intact antibodies (eg., anti-CD3 and anti-CA125) that were coated onto IL-2 activated autologous T-cells. In spite of the high heterogeneity of the resulting bispecific antibodies, advantages of the approach were that only microgram amounts of antibody were required for coating the T-cells and the therapy was considered a cell-based therapy by the FDA since it involved infusion of $\mathrm{T}$-cells and not antibody infusion. Thus, this approach used clinically tested humanized antibodies as a starting point, avoiding 
the need to engineer dual scFVs that may be difficult to express in the amounts needed for therapy. Furthermore, the infusion of bispecific antibody coated T-cells is a cell-based therapy similar, and perhaps complimentary, to infusion of CAR T cells. However, to bring the approach into widespread use, it is important to develop a high yield conjugation method that does not lead to a complex mixture of bispecific antibodies.

To overcome this challenge, we show here an efficient approach to conjugate two antibodies alkylated at their sulfhydryl reduced hinge regions with two complimentary Click reagents, bromoacetamido-dibenzocyclooctyne (DBCO) and

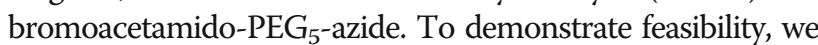
selected the humanized anti-CEA antibody T84.66-M5A (M5A) and anti-CD3 antibody OKT3, both extensively used in the clinic $[9,10]$. Given their dual specificities and retention of bivalent binding, we propose to call them dbBiTEs. The $300 \mathrm{kDa}$ product when purified away from contaminating $150 \mathrm{kDa}$ species, shows distinctive six-lobed antibody particles on electron microscopy that fit atomic scale models, labels both CEA and CD3 positive cells, and when coated on activated T-cells, kills CEA positive cells in cytotoxicity assays. In vivo PET imaging shows excellent targeting to tumor targets, and in the preliminary therapy studies, killing of CEA positive tumors.

\section{Methods}

\section{Materials}

Dibenzocyclooctyne-amine (BP-22066) and bromoacetamido-PEG ${ }_{5}$-azide (BP-21801) were purchased from Broadpharm (San Diego, CA). Murine anti-human CD3 (OKT3; InVivoMAb, BE0001-2) was from BioXCell (Lebanon, $\mathrm{NH}$ ), and rat anti-murine CD3 (Cat no 100331, LEAF purified) from Biolegend (San Diego, CA).

\section{Synthesis of bromoacetamido-DBCO}

To dibenzocyclooctyne-amine (DBCO- $\mathrm{NH}_{2} ; 27.52 \mathrm{mg}$, $0.1 \mathrm{mmol}$ ) in $400 \mu \mathrm{l}$ dry DMF was added bromoacetic anhydride (41.0 mg, $0.15 \mathrm{mmol}$ ) and $\mathrm{NaHCO}_{3}(25.2 \mathrm{mg}$, $0.3 \mathrm{mmol}$ ). After rotating at RT for $2 \mathrm{~h}$ under Argon, the mixture was purified by a Gemini C18 column (Phenomenex, CA. 4.6x250mm) on an Agilent (1260 infinity) HPLC instrument using a mobile phase consisting of $0.1 \%$ TFA $/ \mathrm{H}_{2} \mathrm{O}$ (solvent $\mathrm{A}$ ) and $0.1 \% \mathrm{TFA} /$ acetonitrile (solvent $\mathrm{B}$ ) with a linear gradient from $0 \%$ $\mathrm{B}$ to $95 \% \mathrm{~B}$ in $32 \mathrm{~min}$ at a flow rate of $1 \mathrm{~mL} / \mathrm{min}$. The product (18.7 mg; yield: $47.1 \%$ ) was pooled and stored dried at $4{ }^{\circ} \mathrm{C}$. The mass of the product was confirmed by ESI mass spectrometry on a Thermo LTQ-FT; calculated $\left(\mathrm{M}+\mathrm{H}^{+}\right)$: 397.27, found: 397.06 .

\section{Reduction of hinge cystines in a IgG antibody}

OKT-3 (2 mg, $13.3 \mathrm{nmol})$ in $234 \mu \mathrm{l}$ of PBS was reduced with a $30 \mathrm{M}$ excess of tris (2-carboxyethyl) phosphine
(TCEP) at $37^{\circ} \mathrm{C}$ for $2 \mathrm{~h}$ under Argon. The TCEP was removed by desalting on a spin column (Zeba, $7 \mathrm{kDa} \mathrm{MW}$ cutoff, Thermo Scientific).

\section{Alkylation of a reduced antibody with bromoacetamido- DBCO}

The reduced OKT-3 was reacted with a 20 fold molar excess of bromoacetamido-DBCO at RT overnight under Argon. The excess bromoacetamido-DBCO was removed by dialyzing vs PBS $(2 \mathrm{~L} \times 5)$. The conjugation was confirmed by mass spectrometry on an Agilent 6520 QTOF. There was one DBCO per light chain and four DBCOs per heavy chain.

\section{Alkylation of a reduced antibody with bromoacetamido- PEG $_{5}$-azide}

Humanized anti-CEA antibody M5A (2 mg, $13.33 \mathrm{nmol}$ ) in $400 \mu \mathrm{l}$ of PBS was reduced with a $30 \mathrm{M}$ excess of TCEP at $37^{\circ} \mathrm{C}$ for $2 \mathrm{~h}$ under Argon. The TCEP was removed by desalting on a spin column (Zeba, 7KDa MW cutoff, Thermo Scientific). The reduced M5A was reacted with a 100 fold molar excess of bromoacetamide- $\mathrm{PEG}_{5}-\mathrm{N}_{3}$ at RT overnight under Argon. The excess bromoacetamide- $\mathrm{PEG}_{5}-\mathrm{N}_{3}$ was removed by dialyzing vs PBS $(2 \mathrm{~L} \times 5)$. The conjugation was confirmed by mass spectrometry on an Agilent 6520 QTOF. There was one $\mathrm{PEG}_{5}-\mathrm{N}_{3}$ per light chain and 3 per heavy chain.

\section{Click chemistry and purification by SEC HPLC}

OKT-3-DBCO (2 mg, $13.33 \mathrm{nmol})$ in $360 \mu \mathrm{l} \mathrm{PBS}$ was added to $\mathrm{M} 5 \mathrm{~A}_{-} \mathrm{PEG}_{5}-\mathrm{N}_{3}(2 \mathrm{mg}, 13.3 \mathrm{nmol})$ in $340 \mu \mathrm{l}$ PBS, $\mathrm{pH} 7.25$. The mixture was rotated at $\mathrm{RT}$ for $1 \mathrm{~h}$ under Argon, then incubated at $4{ }^{\circ} \mathrm{C}$ overnight. The clicked antibodies were purified by SEC (Superdex 200, $10 \times 300 \mathrm{GL}, \mathrm{GE}$ Healthcare) at a flow rate of $0.5 \mathrm{ml} /$ min in PBS using a GE AKTAPurifier. Two peaks were collected and concentrated on a $2 \mathrm{~mL}$ Vivaspin 10 MWCO (Sartorius, UK). The molecular sizes of peak 1 $(300 \mathrm{kDa})$ and peak $2(150 \mathrm{kDa})$ were determined by SDS gel electrophoresis (NuPAGE 4-12\% Bis-Tris Gel; Life Technologies, CA) under non-reducing conditions along with antibody standards.

\section{Transmission electron microscopy and image analysis} dbBiTEs were submitted for analysis to Nanoimaging Services, Inc. (San Diego, CA) Samples were prepared on a thin layer of continuous carbon placed over a C-flat holey carbon grid (2.0/1.0; Protochips). A $3 \mu \mathrm{l}$ drop of purified protein $(15 \mu \mathrm{g} / \mathrm{ml}$ in $50 \mathrm{mM}$ Tris/150 mM NaCl, $\mathrm{pH}$ 7.5) was applied to a freshly plasma-cleaned grid for $20 \mathrm{~s}$, blotted to a thin film using filter paper, and immediately stained with $2 \%(\mathrm{w} / \mathrm{v})$ uranyl formate for $1 \mathrm{~min}$. The stain was then blotted away with filter paper and the grid subsequently air-dried. Transmission electron 
microscopy was performed using an FEI Tecnai T12 electron microscope operating at $120 \mathrm{kV}$ equipped with an FEI Eagle $4 \mathrm{k} \times 4 \mathrm{k}$ CCD camera. Images were collected at nominal magnifications of $110,000 x(0.1 \mathrm{~nm} /$ pixel $)$ and $67,000 x(0.16 \mathrm{~nm} /$ pixel $)$ using the automated image acquisition software package Leginon [11]. Images were acquired at a nominal underfocus of $-1.6 \mu \mathrm{m}$ to $-0.9 \mu \mathrm{m}$ or $-1.4 \mu \mathrm{m}$ to $-0.6 \mu \mathrm{m}$ and electron doses of approximately $25 \mathrm{e}-/ \AA^{2}$. An example of a typical field at a magnification of 67,000 is shown in Results.

Image processing was performed using the Appion software package [12]. Contrast transfer functions (CTF) of the images were corrected using CTFFind4 [13]. Individual particles in the 67,000x images were selected using automated picking protocols, followed by several rounds of referencefree 2D alignment and classification based on the XMIPP [14] processing package to sort them into self-similar groups. An example of a 2D reconstructed image in shown in Results. A complete set is available upon request.

A random conical tilt 3D structure analysis was performed on 4000 average particles. Over 50 different RCT reconstructions were computed in an attempt to resolve interpretable structures. Two of the best three-dimensional reconstructions of the cross-linked IgG complex resulted in maps at $45-47 \AA$ resolution using between 644 and 839 particles. The 3D maps of the particles are $150 \AA$ across and reveal structures with five branches of density approximately the size and general shape of Ig domains that define a plane around the periphery of the particle. The position of the sixth Ig domain is disordered in both reconstructions, and is likely either above or below the plane defined by the other Ig domains. The view perpendicular to the plane is flattened in the reconstructed volumes due to limits of the RCT technique, however the central section of the volume had enough additional density to fit most of an Ig domain to sit roughly perpendicular to the orientation of the others, supporting this as the most probable position of the sixth Ig domain in each structure. Density for the Ig domains in each structure varies in both strength and quality and is not sufficient to resolve the hole between the constant and variable domains, and often doesn't allow for the full size of an Ig domain. This observation, along with blurring in the class averages, is an indication of structural heterogeneity and/or flexibility in the particles, and was a complicating factor in computing an interpretable reconstruction. Due to this limitation, it is not possible to identify Fab vs Fc domains, or determine their connectivity in the reconstructed volumes. A complete set of $3 \mathrm{D}$ images is available upon request.

Individual particles were selected using automated picking protocols [12] on both the untilted and tilted images taken at $67,000 x$. Auto alignment was used to match particles across the tilted image pairs [15]. A reference-free alignment strategy based on the XMIPP processing package [14] was used to separate these particles into classes. RCT geometry [16] was used to reconstruct the 3-D structure of the particle pairs in exemplary class averages. The RCT maps presented in this report are based on 644-839 particles. The nominal resolution of both maps is on the order of $\sim 45 \AA$ according to the FSC0.5 resolution criterion. The Chimera visualization package [17] was used to produce the surface renderings of the maps.

\section{Prediction of dbBiTE structure using multiscale simulations}

In brief, the two antibody structures were separately modeled after the available crystal structure of mouse immunoglobulin. The docking between the two antibodies was accomplished using coarse-grain MD simulations, imposing attractive forces among the conjugating cysteine residues in the hinge regions of the two antibodies to facilitate binding. The resulting complex structure was then converted to atomistic resolution for comparison with the EM data.

The structures of the M5A and OKT3 antibodies (Additional file 1: Figure S2A) were predicted using the crystal structure of mouse IgG2a as template (PDB ID: 1IGT) [18], using the software MODELLER [19]. For docking, the two antibodies were initially separated by $100 \AA$ and positioned with their hinge regions facing each other, as shown in Additional file 1: Figure S2A. The system was then converted to the Martini coarsegrained model [20] (Additional file 1: Figure S2B-C) using the CHARMM-GUI [21]. During the course of molecular dynamics, the internal structures of the Fc and Fab regions were preserved using an elastic network [22], while the linker regions were made completely flexible. This allowed us to model the deformation of the hinge regions as the two antibodies approached each other to form the complex. To facilitate docking, we imposed distance restraints between the cysteine residues in the hinge regions of the two antibodies. Each M5A monomer has two cysteines in the lower hinge region connecting heavy chains, while OKT3 has three cysteines connecting two heavy chains. We restrained the $C \alpha$ carbons of the hinge region cysteines of the two antibodies using a flat-bottomed potential with an equilibrium distance of $15 \AA$. Beyond $15 \AA$, the restrained residues experienced an attractive elastic force with a force constant of $1000 \mathrm{KJ} / \mathrm{mol}$, while no forces were experienced below $15 \AA$. The equilibrium distance for the restraint between the conjugated cysteines was determined from MD simulations of two cysteine residues connected by the click chemistry linker in aqueous solution. The equilibrium distance was chosen as the mean value in the distance distribution of the $C \alpha$ carbons in this system (Additional file 1: Figure S2D). 
We hypothesized that upon docking, at least one cysteine in the hinge region of one antibody will be conjugated to one cysteine of the other antibody via click chemistry. To recreate this condition, the system was simulated imposing the criterion that at least one of the distance restraints between the cysteine residues should be satisfied during dynamics.

The system was minimized for 6000 steps using steepest descent minimization, then heated up to $303 \mathrm{~K}$, followed by equilibration in the NPT ensemble for $10 \mathrm{~ns}$ (303 K, $1 \mathrm{~atm})$. During equilibration, the protein atoms were restrained at their initial positions with a force constant of $4000 \mathrm{KJ} / \mathrm{mol}$. The production MD was performed at $303 \mathrm{~K}$ in the NPT ensemble for $500 \mathrm{~ns}$ using a time step of $20 \mathrm{ps}$, by imposing the distance restraints as described above. The MD simulations were performed using GROMACS 5.1 [23]. The final structure from the coarse-grained MD simulation (Additional file 1: Figure $\mathrm{S} 2 \mathrm{E}$ ) was converted to the all-atom structure using the scheme described in ref. [24] and visualized using PyMOL [25].

\section{Tumor cell lines culture and T cell activation}

Human breast carcinoma cell line MDA-MB-231 and human colon carcinoma cell line LS174T were obtained from and validated by ATCC. Murine breast carcinoma cell line E0771 and murine colon cancer cell line MC38 were stably transfected with a CEA expressing plasmid as described earlier [26]. All cell lines were maintained in DMEM supplemented with $10 \%$ fetal bovine serum and $100 \mathrm{U} / \mathrm{ml}$ penicillin/streptomycin. Cell cultures were tested annually for presence of mycoplasm using a mycoplasma detection kit (Universal Mycoplasma Detection Kit, ATCC).

Human PBMC from discard blood (no consent required) were isolated by centrifugation of whole blood on FicolPaque (GE Healthcare) gradient for $30 \mathrm{~min}$ (500 g) and washed with PBS 3 times. After counting and checking cell viability, PBMCs were plated on 6 well plate, previously coated with anti-CD3 antibody $\left(2 \mu \mathrm{g} / \mathrm{mL}\right.$ for $2 \mathrm{~h}$ at $37^{\circ} \mathrm{C}$, washed once with PBS at concentration $2 \times 10^{\wedge} 6 / \mathrm{mL}$ in RPMI1640 containing 10\% FBS and $100 \mathrm{U} / \mathrm{ml}$ of recombinant human IL-2 (BioLegend, San Diego, CA). After $72 \mathrm{~h}$, cultures of activated cells were expanded by platting $5 \times$ $10^{\wedge} 5 / \mathrm{mL}$ in RPMI1640 containing $10 \% \mathrm{FBS}$ and $100 \mathrm{U} / \mathrm{ml}$ of recombinant human IL-2. Cells were cultured for up to 7 days and used for functional experiments in vitro.

Mouse CD3 positive T cells were isolated from spleens collected from CEA transgenic mice using a negative selection kit (Stemcell Technologies, Canada) and plated for activation on 6 well plates previously coated with anti-CD3 antibody (BioLegend, CA; $2 \mu \mathrm{g} / \mathrm{ml}$ for $2 \mathrm{~h}$ in $37 \mathrm{C}$, washed once with PBS), at concentration $2 \times 10^{\wedge} 6 /$ $\mathrm{mL}$ in IMDM containing $10 \%$ FBS and $100 \mathrm{U} / \mathrm{ml}$ of recombinant mouse IL-2 (BioLegend, CA). Cells were cultured for up to 7 days and used for functional experiments in vitro and in vivo.

\section{Coating conditions for dbBiTEs onto activated human or mouse T cells}

Both target cells (human tumor cell lines: MDA-MB$231 \pm \mathrm{CEA}$, mouse tumor cell lines: E0771 \pm CEA, MC38 \pm CEA) and $T$ cells (human PBMCs derived $\mathrm{T}$ cells and mouse CD3 positive cells) were first incubated in $1 \%$ goat serum blocking solution, then stained on ice with $1 \mu \mathrm{g} / \mathrm{mL}$ of dbBiTE in PBS containing $1 \%$ goat serum for $30 \mathrm{~min}$. After washing with PBS, cells were stained on ice for $30 \mathrm{~min}$ with $2 \mu \mathrm{g} / \mathrm{mL}$ of secondary antibodies (all from ThermoFisher): goat anti-mouse Alexa555 and goat anti-human Alexa647 for OKT3M5A dbBiTE; goat anti-rat Alexa555 and goat anti-human Alexa647 antibodies for mCD3-M5A dbBiTE. After washing, cells were resuspended in PBS and analyzed by FACS (LSRFortesa X-20, BD Biosciences). Unstained cells, or cells stained with secondary antibodies only served as negative controls. OKT3 and rat anti mCD3 (BioLegend, CA) and M5A were used as positive controls followed by secondary antibodies staining performed as described above.

\section{In vitro cytoxicity assay}

Target cells were plated on 96-well plates at concentration $10 \times 10^{\wedge} 3$ per well in $100 \mu \mathrm{L}$ of DMEM containing $10 \%$ FBS. After 3 or $18 \mathrm{~h}$, depending on cell line, $100 \mathrm{uL}$ of human activated and antibody coated PBMCs or mouse activated and antibody coated CD3 T cells were added to target cells in concentrations corresponding to final effector to target ratios 10:1, 5:1, 2.5:1 and 1.25:1. Controls with uncoated or anti-CD3 coated cells were used in the same ratios. Cells were co-incubated for $18 \mathrm{~h}$ at $37^{\circ} \mathrm{C}$ followed by analysis of lactate dehydrogenase $(\mathrm{LDH})$ release. The assay was performed following manufacturer's protocol (Takara, Japan) and relative cytotoxicity was calculated according to the same protocol.

\section{In vivo tumor targeting with dbBiTE coated activated mouse T cells}

Mice were chosen as a model system to study tumor growth and response to therapy since they have an intact immune system. These animal experiments were performed using CEA transgenic mice in the C57Bl/6 background generated at the Beckman Research Institute of City of Hope as previously described [26]. Since the CEA gene is not present in mice, it was necessary to use these mice to prevent immunological rejection of CEA as a foreign gene. Mouse care and experimental procedures were performed under pathogen-free conditions in accordance with established institutional guidance and 
approved protocols from the Institutional Animal Care and Use Committee of Beckman Research Institute at City of Hope National Medical Center. Asphyxiation by $\mathrm{CO}_{2}$ and cessation of breathing is an AVMA approved method of euthanasia. For the colon cancer model, MC38/CEA/Luc cells were injected subcutaneously at the concentration of $2 \times 10^{6}$ cells per $0.2 \mathrm{~mL}$. At day 9 post injection optical imaging was performed using the Lago imaging system (Spectral Instruments Imaging, AZ) and treatment groups were assigned base on bioluminescence readings. Mice were treated $4 x$ every 3 days with 10 million activated CD3 T cells with or without dbBITE coating. Four days after the last $\mathrm{T}$ cell injection the tumor nodules were counted and removed, then dissociated by enzymatic digestion using gentleMacs Octo Dissociator and dissociation kit following the manufacture's protocol (Miltenyi Biotec). Nodule size comparisons were analyzed by a paired T-test. Samples were analyzed by flow for presence of DAPI negative, live cells, CD45 positive or CEA positive cells. CD45 cells were further analyzed for CD8 and CD4 markers, and CD11b positive myeloid cells were analyzed for Ly6G (neutrophil) and F4/ 80 (macrophage) markers.

\section{PET imaging of a CEA positive tumor with ${ }^{64} \mathrm{Cu}$ radiolabed DOTA-dbBiTE}

dbBiTEs were conjugated with NHS-DOTA as previously described [27]. Immunoreactivity to CEA was confirmed by addition of ${ }^{64} \mathrm{Cu}$-DOTA-dbBiTE to CEA followed by SEC as shown in Additional file 1: Figure S5C. Animal imaging studies were performed in NOD/SCID mice (Jackson Laboratory) bearing s.c. LS-174 T CEA positive tumors as previously described [27]. PET scans were acquired with an Inveon microPET/CT scanner (Siemens Medical Solutions). Mice were anesthetized with $2-4 \%$ isoflurane in oxygen, placed on the PET scanner, and injected with a single intravenous dose of $100 \mu \mathrm{Ci}(10 \mu \mathrm{g})$ of ${ }^{64} \mathrm{Cu}$-DOTA-dbBiTE in $1 \%$ human serum albumin-buffered saline through a tail vein catheter. At the terminal time point, the mice were euthanized and biodistribution studies performed on the tissues indicated in Additional file 1: Figure S6.

\section{Results}

\section{Generation of dbBiTES}

Building on the approach developed by Lum et al. [4] who randomly cross-linked two intact antibodies (anti-CD3 and anti-CA125) using Traut's reagent and sulfosuccinimidyl 4-( $N$-maleimidomethyl) cyclohexane-1-carboxylate to redirect $\mathrm{T}$-cell therapy to tumor targets, we first generated bispecific antibodies by cross-linking two intact antibodies at their hinge regions using Click chemistry (Scheme 1). The use of Click chemistry allows the generation of a bispecific antibody product with improved yields and molecular characteristics, a much-desired feature in bringing new products to the clinic. To distinguish the product from conventional BiTEs built from monovalent single chain $\mathrm{Fv}$ (scFv) fragments, we suggest the name dbBiTE, for dual specific bivalent BiTE. Briefly, OKT3, a murine anti-human CD3 antibody widely used in the clinic [9] was reduced at its hinge region cystines under non-denaturing conditions, alkylated at the reduced hinge region cysteines with a bromoacetamido- PEG $_{5}$-azido derivative and conjugated to our humanized anti-CEA M5A antibody [10] that was similarly reduced and alkylated with a bromoacetamido-DIBO derivative. Each of the derivatized IgGs were analyzed by electrospray ionization mass spectrometry to confirm their degree of derivatization (Additional file 1: Figure S1). In both cases the heavy chains contained at least 2 Click derivatives. The Clicked dbBiTE was isolated in a yield of $30 \%$ by size exclusion chromatography (SEC, peak 1, 300 kDa, Fig. 1a). A second peak of MW $150 \mathrm{kDa}$ was obtained in a yield of $60 \%$. The peaks were analyzed by non-denaturing SDS gel electrophoresis to further verify their molecular sizes compared to the two intact antibodies (Fig. 1b and c). The $150 \mathrm{kDa}$ peak was shown to be a mixture of unreacted IgGs and monovalent bispecific antibodies that were poorly active in functional studies (redirected T-cell cytotoxicity) and was broken down into lower molecular weight fragments by SDS gel electrophoresis (Fig. 1b). Therefore, we focused on the novel dbBiTE $(300 \mathrm{kDa})$ since it retains the inherent avidity (bivalent binding) of both parent antibodies. Peak 1 was re-purified by SEC to remove contaminating peak 1 . Rechromatography of peak 1 over the course of several weeks showed no evidence of instability consistent with their covalent linkages (data not shown). Rechromatography of peak 2 over a similar period revealed about $20 \%$ additional conversion to peak 1 (data not shown).

\section{Particle size by transmission electron microscopy}

Purified peak 1 was analyzed by transmission electron microscopy (TEM) to determine the particle size and morphology (Fig. 2a). Most particles exhibited a 5-lobed morphology suggesting that the predicted sixth lobe (based on 3 lobes per $\mathrm{Ab}$ times $2 \mathrm{Ab}$ ) was hidden under or above the plane of the $2 \mathrm{D}$ image. This morphology is more clearly visualized on the $2 \mathrm{D}$ averaged analysis (Fig. 2b). Using tilt axis imaging, it was possible to show a representative $3 \mathrm{D}$ image (Fig. 2c). A closer examination of the particles shown in Fig. 2a reveals multiple orientations of 6-lobed particles (further data available upon request), always with the sixth lobe appearing as additional density in the center of the particle. These images are compatible with the random landing of 6-lobed 3D particles on a 2D grid in which one lobe is lying above or below the main body of the particle. In addition to the majority of 6-lobed particles found, a small percentage $(<10 \%)$ of particles with a side-to side 


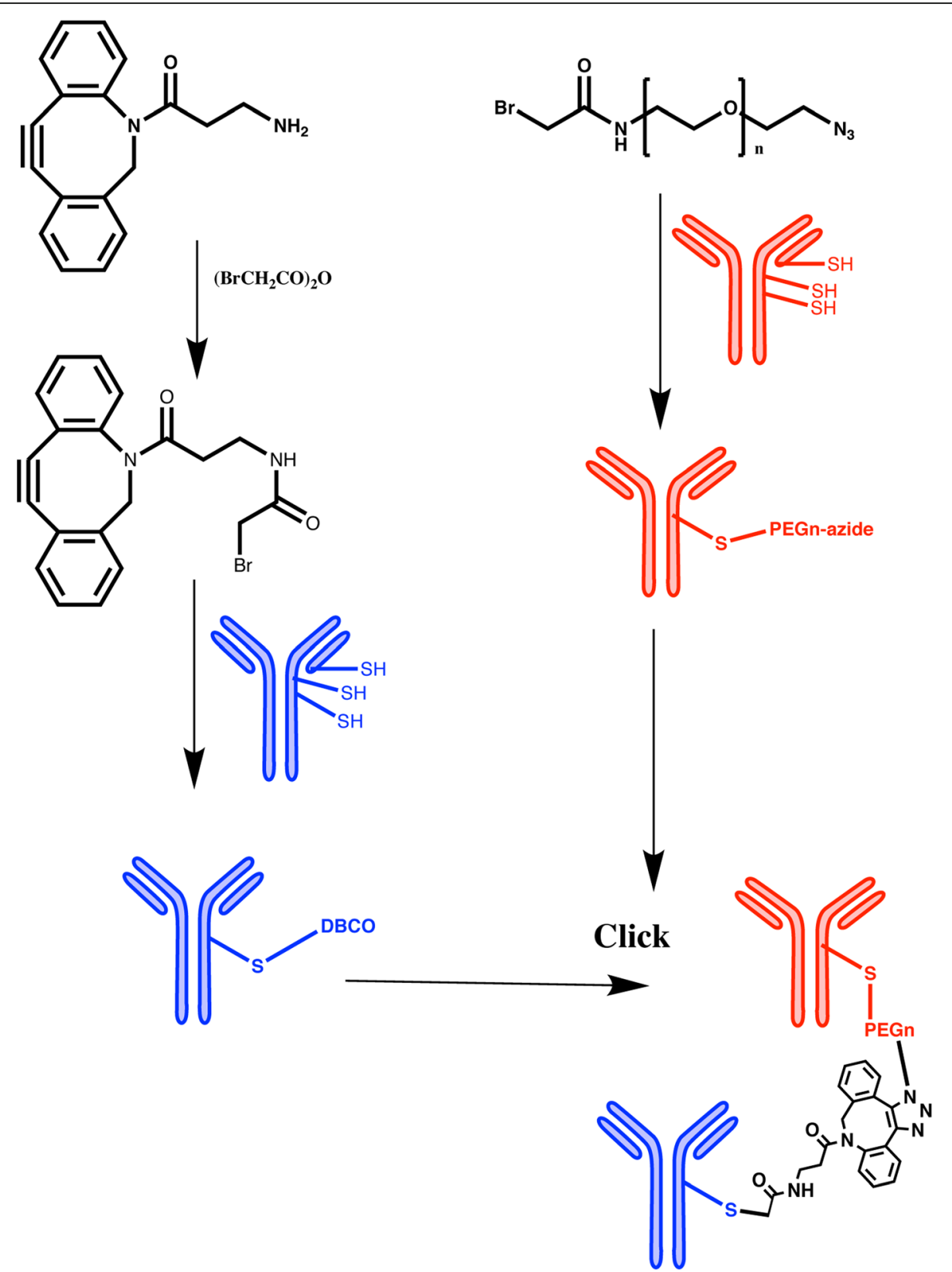

Scheme 1 Cysteine hinge specific Click chemistry for generation of dbBiTES. Blue = reduced antibody 1 with DBCO. Red = reduced antibody 2 with $P E G_{n}$-azide. Click = the two derivatized antibodies were mixed 1:1. The cross-linking between two heavy chains is likely the favored result, including the possibility of two heavy chain cross-links per dbBiTE. Evidence for cross-linking between two light chains (side to side) is shown in the EM studies as a rare event

orientation were observed. We speculate that these are due to Click chemistry occurring between adjacent light chains (1 cysteine per light chain) at their hinge regions, rather than the more frequent heavy chain hinge regions (3 cysteines per heavy chain in human IgG1).

\section{Molecular simulations of dbBiTE structure}

We performed multi-scale molecular dynamics simulations to generate an atomic level structural model examining how the two IgGs fit into a dbBiTE joined by Click chemistry at their hinge region cysteines. We generated a coarse grain homology model of the two IgGs (Additional file 1: Figure S2) that used the coarse grain simulation method Martini to optimize the packing of these two moieties. The dynamics of the two IgGs approaching each other and docking at their hinge regions is shown in Additional file 2: Movie S1. The optimized structural model shows the two IgGs joined by 

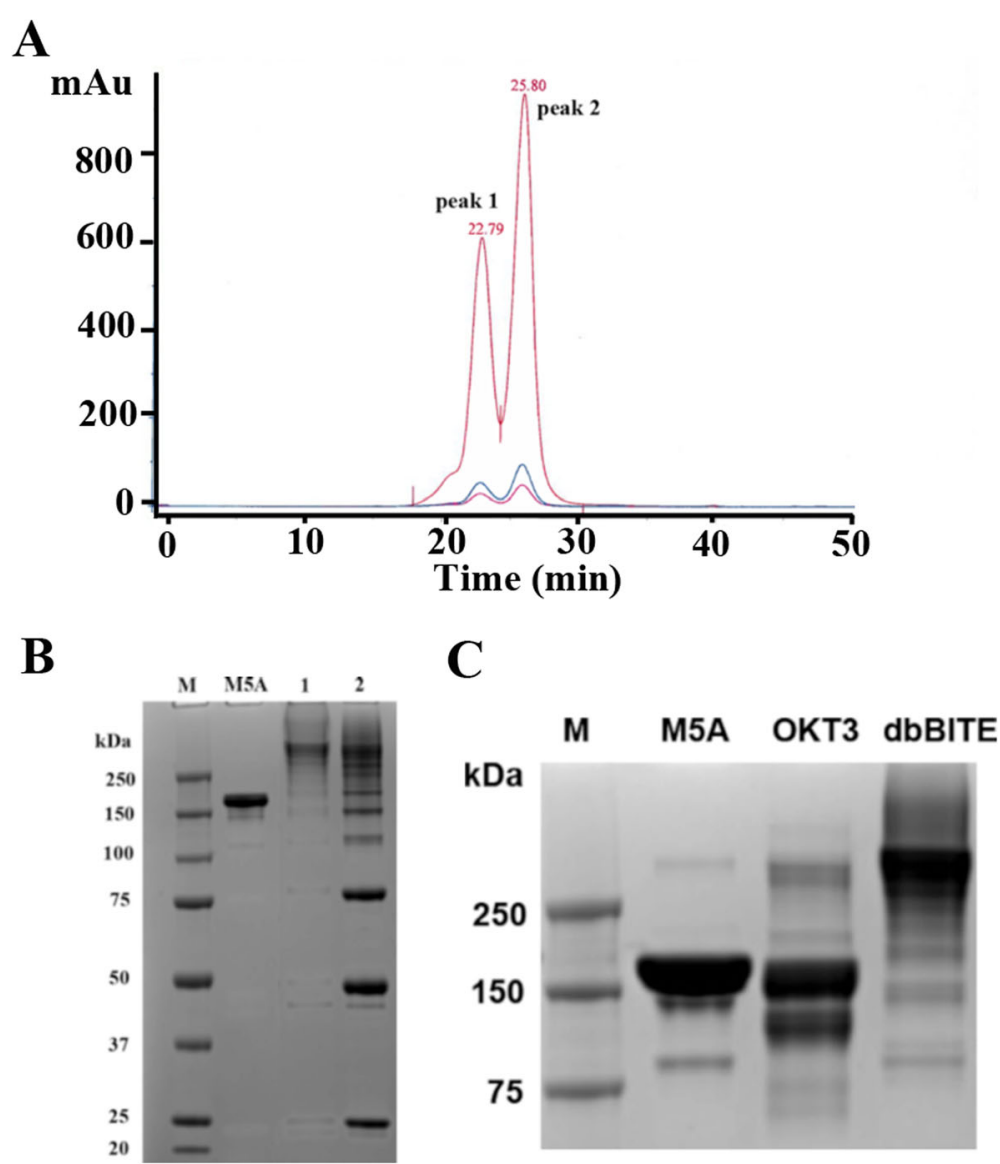

Fig. 1 Purification of a dbBiTE by size exclusion HPLC. a One hundred micrograms of a crude reaction mixture of DBCO-anti-CD3 antibody plus azido-PEG -anti-CEA antibody were injected onto a Superdex $200(1 \times 30 \mathrm{~cm})$ column, monitored at $214 \mathrm{~nm}$ (red) and $280 \mathrm{~nm}$ (blue) and eluted at a flow rate of $0.5 \mathrm{~mL} / \mathrm{min}$ in PBS. The two peaks (peak 1 and 2) were collected and further analyzed. Based on calibration with authentic standards, peak 1 has a molecular mass of $300 \mathrm{kDa}$ and peak 2, $150 \mathrm{kDa}$. b Peaks 1 and 2 from SE HPLC were run on non-reducing SDS gels to determine their molecular sizes compared to the standard IgG M5A. c The starting antibodies, anti-CEA M5A and anti-CD3 OKT3 were run as standards on SDS polyacrylamide gel electrophoresis alongside purified peak $1 \mathrm{dbBiTE}$

at least two pairs of Clicked hinge region cysteines (Fig. 3, Additional file 3: Movie S2 and Additional file 4: Movie S3). The final docked dbBiTES were then oriented to fit within the observed 6-lobed particles found on EM (Additional file 1: Figure S3). The superposition of the dbBiTE structural model thus generated, onto the particles imaged by EM strongly supports the idea that two IgGs can indeed be joined together at their hinge regions in spite of the size of their 3 globular domains.

\section{In vitro binding and cytotoxicity of dbBiTEs to CEA positive targets}

Since it was important to demonstrate that both antibody specificities were retained in the dbBiTE, in vitro binding studies were performed comparing the starting antibodies to the dbBiTE on CEA and CD3 positive targets (Fig. 4a-b). The results demonstrate that dbBiTES are able to bind both CEA and CD3 positive target cells.
In vitro cytotoxicity was demonstrated by coating activated human T-cells with dbBiTES $(1 \mu \mathrm{g}$ per $10 \mathrm{M}$ cells per $\mathrm{mL}$ ) and incubation with CEA positive targets at the indicated $\mathrm{E}: \mathrm{T}$ ratios (Fig. 4c). Effective killing was observed as low as an E:T of 1.25:1 with maximal killing at an E:T of 10:1. Analysis of the supernatants revealed a significant release of IFN $\gamma$ compared to controls (Fig. 4d) demonstrating that the dbBiTE coated activated T-cells were able to produce a functional cytokine in response to target engagement. When the coating capacity of activated T-cells with dbBiTEs was tested by flow analysis, it was found that as little as $1 \mathrm{ng} / \mathrm{mL}$ of dbBiTE incubated with $10 \mathrm{M} \mathrm{T}$ cells per $\mathrm{mL}$ was detectable (Fig. 4e). Although the cytotoxicity of activated T-cells against CEA positive targets was detectable at this concentration, higher coating concentrations were more effective (Fig. 4f). Microscopic images of the killing of CEA positive 


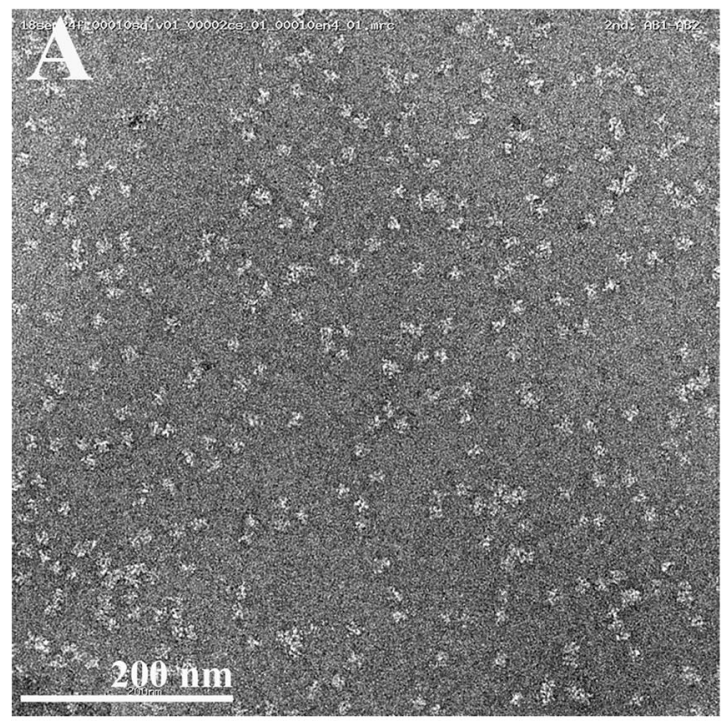

\section{B}
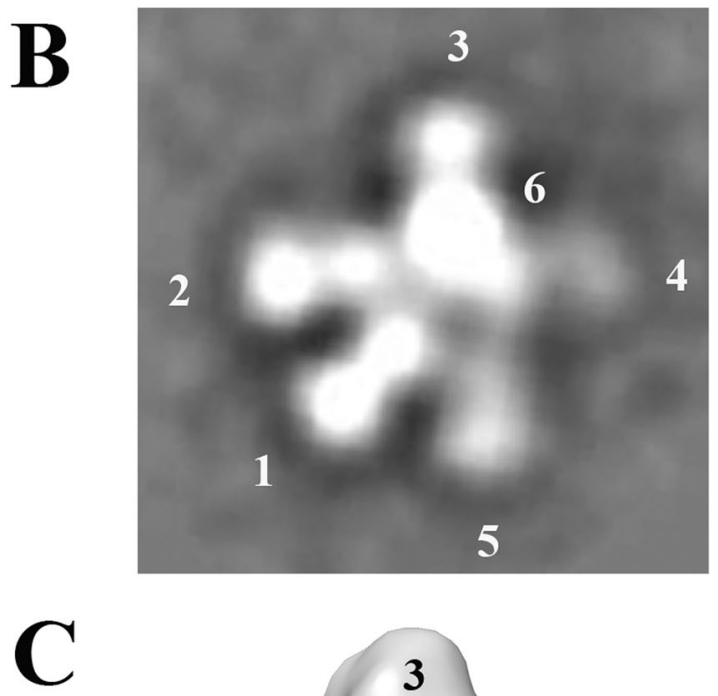

6

\section{2} gated half molecules. Since only the $300 \mathrm{kDa}$ species shifted to a higher molecular complex on the addition of unlabeled CEA, we conclude that only the $300 \mathrm{kDa}$ dbBiTE is immunoreactive.

When ${ }^{64} \mathrm{Cu}$-DOTA labeled dbBiTE was injected into CEA positive tumor bearing mice, PET imaging revealed rapid uptake into both tumor and liver with evidence of blood pool in the heart at the earliest time point (Additional file 1: Figure S6). At the terminal time of $44 \mathrm{~h}, 15 \% \mathrm{ID} / \mathrm{g}$ was found in tumor, $5 \% \mathrm{ID} / \mathrm{g}$ in blood and $18 \% \mathrm{ID} / \mathrm{g}$ in liver. Compared to our previously published PET images of ${ }^{64} \mathrm{Cu}$-DOTA labeled M5A that showed about $45 \% \mathrm{ID} / \mathrm{g}$ in tumor, $10 \% \mathrm{ID} /$ in blood and $12 \% \mathrm{ID} / \mathrm{g}$ in liver at $44 \mathrm{~h}[27]$, the faster clearance of dbBiTE from blood into liver may be due to liver recognition of the multiple Fc moieties on the dbBiTE. Nonetheless, the PET imaging demonstrates excellent targeting of the dbBiTE to tumor, encouraging us to test the efficacy of the dbBiTE in vivo.

\section{In vivo killing of CEA positive tumors}

A limited therapy study of dbBiTE coated T-cells was performed in CEA transgenic mice bearing the syngeneic colon cancer cell line MC38 transfected with CEA and luciferase. This model (minus the luciferase) has been previously described by us using the immunocytokine anti-CEA-IL-2 [26]. In order to test a biocompatible version of the dbBiTE in this model system, we generated a 

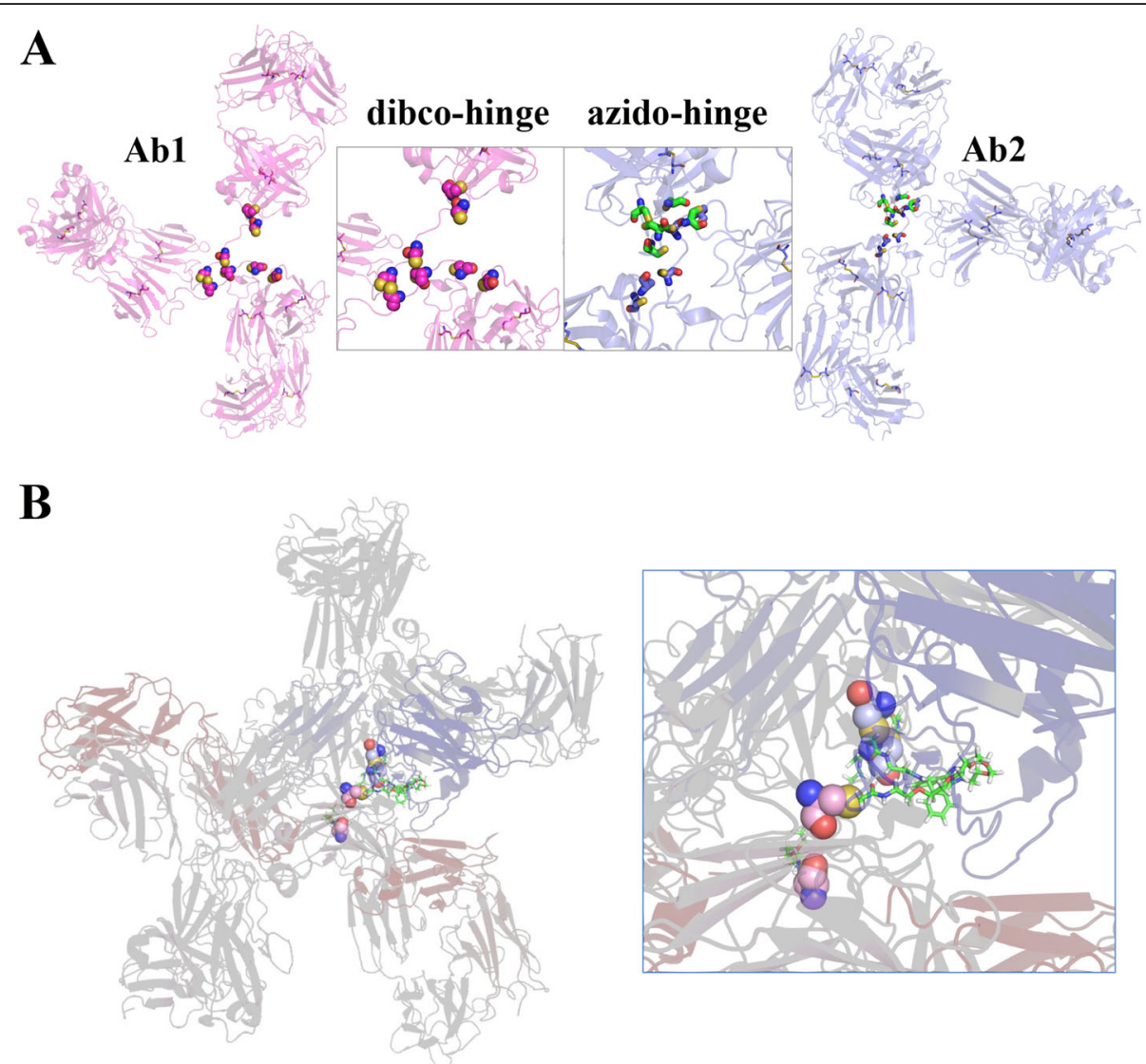

Fig. 3 Structural model of the dbBiTE. a Details of the hinge region. The two Clicked reagents, DBCO and PEG -azide are shown attached to cysteines in the hinge regions of two IgG1s. b Structural model derived after coarse grain MD simulations showing possible Clicked derivatives between two pairs of cysteines in the heavy chain hinges of a dbBiTE

dbBiTE comprising rat anti-mouse CD3 and anti-CEA M5A (data not shown). The in vitro cytotoxicity of this dbBiTE was first demonstrated with two CEA transfected cell lines, murine mammary carcinoma line E0177 and murine colon carcinoma line MC38, compared to untransfected parental cells (Additional file 1: Figure S7). Tumors were inoculated i.p. and 3 mice were selected as controls (little or no luciferase expression after 9 days) and 3 with carcinomatosis (Fig. 5a). The mice were treated i.p. four times every 3 days with $10 \mathrm{M}$ activated murine spleen $\mathrm{T}$-cells either coated or not with $1 \mu \mathrm{g}$ of dbBiTE. Four days after the last injection of dbBiTE coated T-cells, the mice were euthanized and examined for the presence of tumor nodules. The number of tumor nodules that were found either peri-pancreatic or peri-intestinal are shown in Fig. $5 \mathrm{~b}$ along with micrographs shown in Fig. $5 \mathrm{c}$ and e. At the terminal point of the study, the tumor nodules were found predominately in close proximity to pancreas (Fig. 5c) with an average of 6 nodules per mouse in the control group and none in the dbBiTe treated group. The bioluminescence signal from that region was already present at the time of group assignment in both groups as shown in Fig. 5a. The intestinal location represented a second region with tumor nodules seen both at the time of group assignment as well as at the terminal point necropsy.

Tumor nodules were then digested and analyzed by flow for the presence of CEA, CD45 lymphocytes, CD4 or CD8 T-cells, and Ly6G neutrophils or F4-80 macrophages (Fig. 5d and f). The results demonstrate an absence of CEA in dbBiTE treated tumors and infiltration of $\mathrm{Ly} 6 \mathrm{G}^{+}$neutrophils, while CEA is present in controls along with infiltration of $\mathrm{F} 4 / 80^{+}$macrophages. Although this is a very preliminary therapy study, we are encouraged that dbBiTE coated T-cells may have therapeutic potential, and with further development, become an alternative to the genetic manipulation necessary with CAR T-cell therapy.

\section{Discussion}

This study was initiated to extend the scope of BiTEs beyond the technology requiring genetically engineered dual scFvs, and beyond the approach of coating activated 


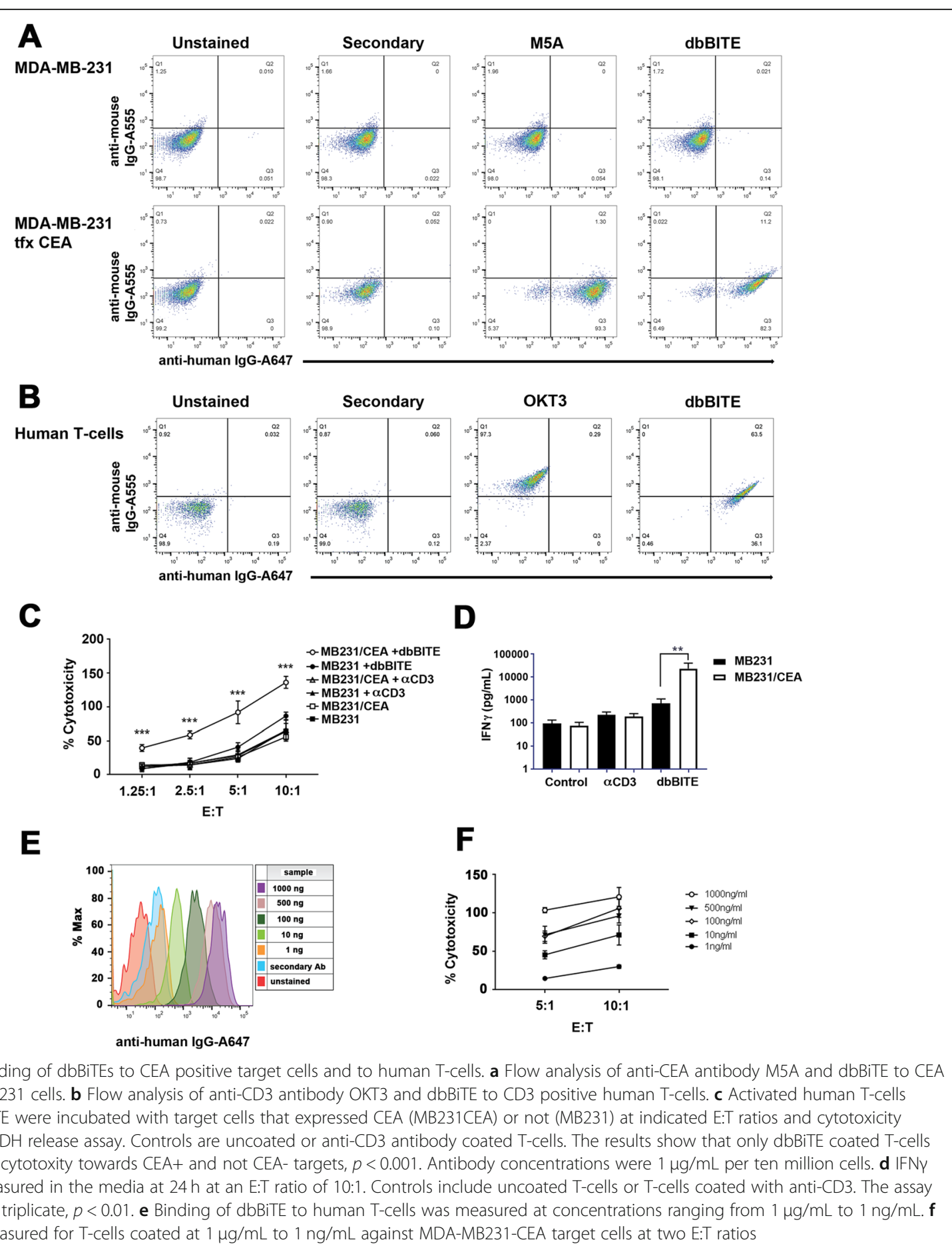

T-cells with a heterogenous mixture of bispecific antibodies. While genetically engineered BiTEs from dual $\mathrm{scFv}$ fragments to $\mathrm{CD} 3$ and either EpCAM or CD19 have shown significant anti-tumor activity in the clinic [28-30], it is advantageous to utilize readily available intact tumor specific antibodies. In this regard, CEA is an excellent target for many solid tumors including colon, breast, pancreas, and medullary thyroid carcinoma [31].
Although several groups have generated anti-CD3/antiCEA dual scFv BiTEs [32, 33], their clinically utility is subject to several challenges common to all dual scFv BiTES. A major challenge is that the production of dual scFv BiTEs requires proper protein folding for subsequent large-scale production for clinical use. A second challenge is the need to continuously infuse these BiTEs for therapy due to their rapid blood clearance via the 


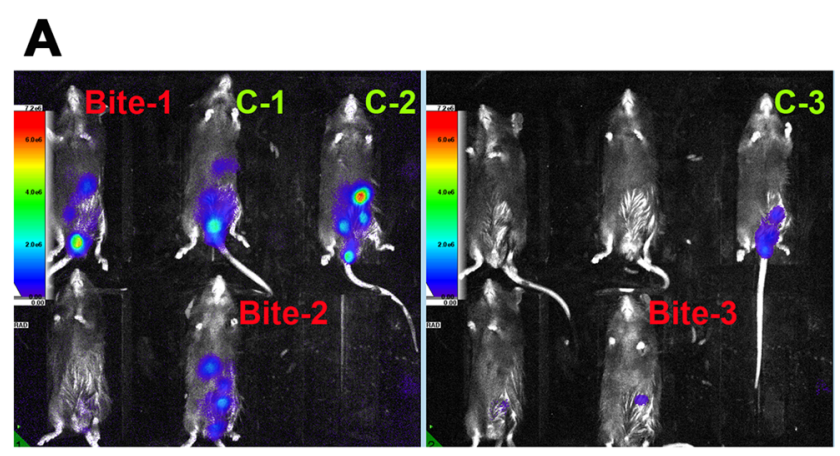

B

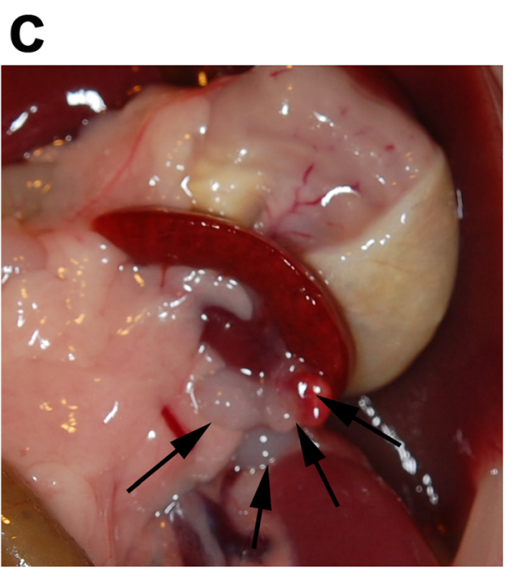

D
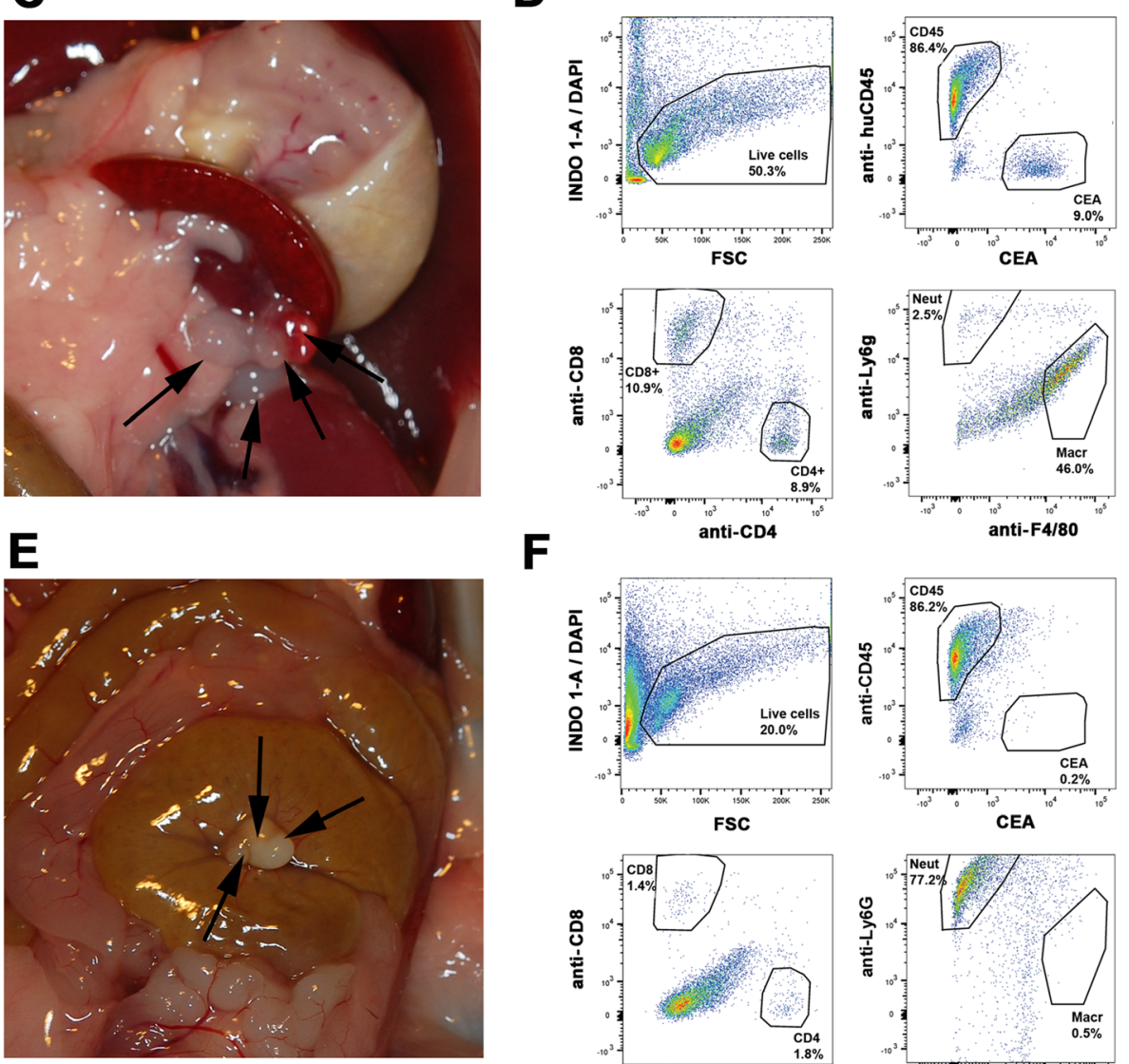

$\mathbf{F}$

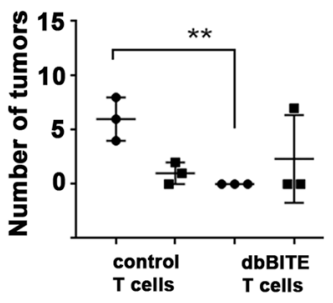

- panreatic region

- small intestinal region
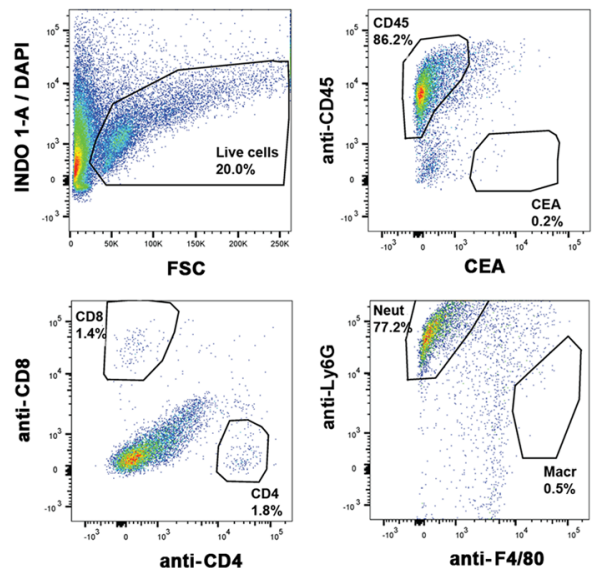

Fig. 5 In vivo activity of dbBiTE coated murine T-cells against CEA targets in a CEA transgenic mouse model. a Optical imaging of CEA-Tg mice injected i.p. with mouse carcinoma cell line MC38-CEA-Luc at day 9 post injection. Labels: Controls in green and dbBiTE in red indicate group assignments. Mice without detectable bioluminescence were not used. b Number of tumor nodules in pancreas or intestine region in CEA-Tg mice treated 4x every 3 days with 10 million activated CD3 T cells with or without dbBiTE coating. c Tumor nodules indicated by arrows found in peri-pancreatic location of mouse treated with control T cells. $\mathbf{d}$ Flow analysis of digested tumor nodules from animals treated with control T-cells (shown in c). Samples were analyzed for presence of DAPI negative live cells, CD45 positive or CEA positive cells. CD45 cells were further analyzed for presence of CD8 and CD4 markers, and CD11b positive myeloid cells were checked for Ly6G and F4/80 markers. e Tumor nodules in peri-intestine location (arrows) of mouse treated with dbBiTE coated T cells. $\mathbf{f}$ Flow analysis of tumor nodules (shown in e) using the same staining and gating as in panel (d). Note: tumor nodules were in the range of 2-3 mm diameter determined at the time of necropsy. Due to tumor location and skin color of the mice, bioluminescence measurements were only used to assign mice to groups at the onset of the study

kidney. Since many humanized anti-tumor antibodies have become FDA approved therapeutics, it is highly desirable to generate bispecific antibodies directly from intact antibodies circumventing these two problems. First, there is no need to re-engineer the bispecific BiTE, and if an intact anti-tumor IgG is FDA approved, one 
may obtain it from the pharmacy. Similarly, a murine anti-human CD3 antibody is commercially available and clinically tested [34]. Second, once combined into a bispecific format, their combined molecular weights (300 kda) would preclude blood clearance by the kidney.

Although an attractive idea, many attempts to produce such antibodies retaining their dual specifities has revealed inherent limitations. Among the approaches, knobs-into-holes [35], DuoBody [36], and Cross-Mabs [37], all require re-engineering the parent antibodies. Several chemical cross-linking strategies have been explored, one of which reached the stage of clinical trials. The strategy involved the introduction of protein surface thiols by reaction of surface lysines on IgGs with Traut's reagent, followed by the hetero-bispecific crosslinking agent sulfosuccinimidyl 4 -( $N$-maleimidomethyl) cyclohexane-1-carboxylate [4]. Although the cross-linked product had significant anti-tumor activity when coated on activated T-cells, the product itself was very heterogeneous. A better strategy at producing a more homogeneous cross-linked product was described by Patterson et al. for two IgGs [38] and their Fab fragments [38]. In this approach chemically reduced hinge region cysteines were derivatized with Click reagents that allowed a more specific crosslinking of two different IgGs together. In their study, two clinically available anti-tumor antibodies, anti-EGFR (Cetuximab) and anti-Her2 (Trastuzuab), that were conjugated by cysteine specific Click chemistry retained the specificities of both intact antibodies.

In our study, we demonstrate that cross-linking of murine anti-human OKT3, an IgG2a, to a humanized anti-CEA IgG1 resulted in a bispecific antibody that was isolated in high yield and retained high binding to cells expressing human CD3 or CEA. Importantly, since both antibodies retain both antigen-combining arms, they retain the property of avidity, inherent to all intact antibodies, a feature that is lost with dual scFv BiTEs. To emphasize this feature, we have named them dbBiTES for their dual specific, bivalent properties. Since biological products are expected to meet high standards in terms of molecular characterization, it was important to analyze the physical characteristics of dbBiTEs. TEM characterization of the resultant 300 $\mathrm{kDa}$ particles revealed a flexible six-lobed structure with considerable density at the hinge region, consistent with our expected model. Indeed, the structural model generated using molecular docking and dynamics of the two IgG antibodies was consistent with the TEM analysis. Finally, dbBiTE coated human or murine $\mathrm{T}$-cells demonstrated significant and specific anti-CEA cytoxicity for CEA positive target cells. Thus, this approach may be exploited to generate antibody directed activated $\mathrm{T}$ cells without the need for genetic engineering, or alternatively, may be used to coat CAR$\mathrm{T}$ cells to give them additional properties.

Since dbBiTEs are at an early stage of development, it remains to demonstrate all of their advantages and/or to predict all of their disadvantages. For example, the presence of intact Fc domains may be viewed as either an advantage or a disadvantage, depending on the need to engage, or not, Fc receptors. One clue to their in vivo function was the difference in recruitment of myeloid cells to tumors treated in vivo. dbBiTE coated T-cells appeared to dramatically increase neutrophil infiltration, while in controls, macrophage infiltration dominated. We speculate that their Fc regions may have played a role in this result. Clearly, more model systems need to be tested to determine if this dichotomy can be generalized and if it truly reflects the Fc activity of dbBiTEs. Overall, we believe this powerful approach can be generalized, since it was demonstrated for both all-human and all-murine IgG systems.

\section{Conclusion}

This study presents an efficient approach to the generation of BiTEs from readily available intact IgGs with clinical tested properties such as $\mathrm{T}$-cell binding in the case of OKT3, and tumor antigen targeting in the case of anti-CEA M5A. The method described for the production of dbBiTEs should be widely applicable to a wide range of IgGs. The characterization provided includes analysis of the product by TEM, and supporting in vitro studies demonstrate their functional properties. PET imaging studies show excellent tumor targeting in vivo, while preliminary studies suggest that they also possess potent anti-tumor activity.

\section{Additional files}

Additional file 1: Figure S1. ESI MS analysis of DBCO and PEG 5 azido derivatized antibodies. A-B. Figure S2. Molecular dynamic simulation of the formation of dbBiTES. Figure S3. Superposition of dbBiTE model onto an average EM particle. Figure S4. Microscopic imaging of dbBiTE coated T-cells killing target cells. Figure S5. SEC analysis of ${ }^{64} \mathrm{Cu}$-DOTA labeled M5A and dbBiTE. Figure S6. In vivo targeting of ${ }^{64} \mathrm{Cu}$-DOTAdbBiTE in NOD-SCID mice bearing CEA positive LS-174 T tumors. Figure S7. Binding of dbBiTE rat-anti-murine CD3-human anti-CEA (M5A) to murine target cells \pm CEA and cytotoxicity. (PDF 15021 kb)

Additional file 2: Movie S1. Coarse grain simulation of docking of two antibodies. (MPG $39715 \mathrm{~kb}$ )

Additional file 3: Movie S2. Predicted atomistic structure of dbBITE using multiscale simulations. (MP4 $4778 \mathrm{~kb}$ )

Additional file 4: Movie S3. Predicted atomistic structure of dbBITE shown in molecular surface representation. (MOV 19114 kb)

Additional file 5: Movie S4. Time lapse photography of dbBiTE coated human T-cells ( 1 $\mu \mathrm{g} / 10 \mathrm{M}$ cells) killing MDA MB231/CEA target cells. (MP4 $13237 \mathrm{~kb})$

Additional file 6: Movie S5. Time lapse photography of dbBiTE coated human T-cells ( $1 \mu \mathrm{g} / 10 \mathrm{M}$ cells) incubated with MDA MB231 control cells. (MP4 13273 kb) 


\section{Abbreviations}

CEA: Carcinoembryonic antigen or CEACAM5; dbBiTE: Dual binding bivalent bispecific T-cell engager; DBCO: Dibenzocyclooctyne; DOTA: 1,4,7,10Tetraazacyclododecane-1,4,7,10-tetraacetic acid; FBS: Fetal bovine serum; HPLC: High performance liquid chromatography; IgG: Immunoglobulin; SEC: Size exclusion chromatography; TEM: Transmission electron microscopy

\section{Acknowledgements}

We acknowledge preliminary TEM studies by the City of Hope EM Core and the mass spectrometry City of Hope proteomics core.

\section{Authors' contributions}

JES conceived the idea. MK, LL, and SB designed and carried out experiments. W-HL, LW (nee LO), and HL performed in vitro and in vivo studies. Radiolabeling, imaging, and biodistribution studies were performed by $J C, K P, N B$, and PW. VN supervised and critiqued the molecular dynamics studies. PY provided the humanized anti-CEA antibody M5A and critical review of the manuscript. All authors have read and approved the manuscript.

\section{Funding}

The authors thank the City of Hope Comprehensive Cancer Center (NCl grant P30 CA033572) for support. NIH had no role in the design of this study, the collection of data, analysis, and interpretation in the writing of this manuscript.

\section{Availability of data and materials}

All original data can be obtained by writing jshively@coh.org.

\section{Ethics approval}

The animal studies were carried out according to the Guide for the Care and Use of laboratory Animals of national Institutes of Health. The protocol number 13024 was approved by the Institutional Animal Care and Use Committee (IACUC) of City of Hope, an AAALAC approved facility (assurance number A3001-01). None of the cell lines used required ethical approval.

\section{Consent for publication}

Not applicable.

\section{Competing interests}

The authors declare that they have no competing interests.

\section{Author details}

'Department of Molecular Imaging and Therapy, Beckman Research Institute City of Hope, Duarte, CA 91010, USA. ²Department of Computational and Quantitative Medicine, Beckman Research Institute City of Hope, Duarte, CA 91010, USA. ${ }^{3}$ Radiopharmacy, Beckman Research Institute City of Hope, Duarte, CA 91010, USA.

Received: 14 March 2019 Accepted: 19 August 2019 Published online: 05 September 2019

\section{References}

1. Baeuerle PA, Reinhardt C. Bispecific T-cell engaging antibodies for cancer therapy. Cancer Res. 2009;69(12):4941-4

2. Yu L, Wang J. T cell-redirecting bispecific antibodies in cancer immunotherapy: recent advances. J Cancer Res Clin Oncol. 2019;145(4):941-56.

3. Klinger M, Benjamin J, Kischel R, Stienen S, Zugmaier G. Harnessing T cells to fight cancer with BiTE(R) antibody constructs--past developments and future directions. Immunol Rev. 2016;270(1):193-208.

4. Chan JK, Hamilton CA, Cheung MK, Karimi M, Baker J, Gall JM, Schulz S, Thorne SH, Teng NN, Contag CH, et al. Enhanced killing of primary ovarian cancer by retargeting autologous cytokine-induced killer cells with bispecific antibodies: a preclinical study. Clin Cancer Res. 2006;12(6):1859-67.

5. Gall JM, Davol PA, Grabert RC, Deaver M, Lum LG. T cells armed with antiCD3 $x$ anti-CD20 bispecific antibody enhance killing of CD20+ malignant B cells and bypass complement-mediated rituximab resistance in vitro. Exp Hematol. 2005:33(4):452-9.

6. Davol PA, Smith JA, Kouttab N, Elfenbein GJ, Lum LG. Anti-CD3 $x$ antiHER2 bispecific antibody effectively redirects armed $T$ cells to inhibit tumor development and growth in hormone-refractory prostate cancer- bearing severe combined immunodeficient beige mice. Clin Prostate Cancer. 2004;3(2):112-21.

7. Reusch U, Sundaram M, Davol PA, Olson SD, Davis JB, Demel K, Nissim J, Rathore R, Liu PY, Lum LG. Anti-CD3 x anti-epidermal growth factor receptor (EGFR) bispecific antibody redirects T-cell cytolytic activity to EGFR-positive cancers in vitro and in an animal model. Clin Cancer Res. 2006;12(1):183-90.

8. Zitron IM, Thakur A, Norkina O, Barger GR, Lum LG, Mittal S. Targeting and killing of glioblastoma with activated T cells armed with bispecific antibodies. BMC Cancer. 2013;13:83.

9. Ortho Multicenter Transplant Study G. A randomized clinical trial of OKT3 monoclonal antibody for acute rejection of cadaveric renal transplants. $\mathrm{N}$ Engl J Med. 1985;313(6):337-42.

10. Yazaki PJ, Sherman MA, Shively JE, Ikle D, Williams LE, Wong JY, Colcher D, Wu AM, Raubitschek AA. Humanization of the anti-CEA T84.66 antibody based on crystal structure data. Protein Eng Des Sel. 2004;17(5):481-9.

11. Suloway C, Pulokas J, Fellmann D, Cheng A, Guerra F, Quispe J, Stagg S, Potter CS, Carragher B. Automated molecular microscopy: the new Leginon system. J Struct Biol. 2005;151(1):41-60.

12. Lander GC, Stagg SM, Voss NR, Cheng A, Fellmann D, Pulokas J, Yoshioka C, Irving C, Mulder A, Lau PW, et al. Appion: an integrated, database-driven pipeline to facilitate EM image processing. J Struct Biol. 2009;166(1):95-102.

13. Rohou A, Grigorieff N. CTFFIND4: fast and accurate defocus estimation from electron micrographs. J Struct Biol. 2015;192(2):216-21.

14. Sorzano CO, Marabini R, Velazquez-Muriel J, Bilbao-Castro JR, Scheres SH, Carazo JM, Pascual-Montano A. XMIPP: a new generation of an open-source image processing package for electron microscopy. J Struct Biol. 2004; 148(2):194-204.

15. Voss NR, Yoshioka CK, Radermacher M, Potter CS, Carragher B. DoG picker and TiltPicker: software tools to facilitate particle selection in single particle electron microscopy. J Struct Biol. 2009;166(2):205-13.

16. Radermacher M, Wagenknecht $\mathrm{T}$, Verschoor A, Frank J. Threedimensional reconstruction from a single-exposure, random conical tilt series applied to the 505 ribosomal subunit of Escherichia coli. J Microsc. 1987;146(Pt 2):113-36.

17. Goddard TD, Huang CC, Ferrin TE. Visualizing density maps with UCSF chimera. J Struct Biol. 2007;157(1):281-7.

18. Harris $L$, Larson SB, Hasel KW, McPherson A. Refined structure of an intact lgG2a monoclonal antibody. Biochemistry. 1997;36(7):1581-97.

19. Sali A, Blundell TL. Comparative protein modeling by satisfaction of spatial restraints. J Mol Biol. 1993;234(3):779-815

20. Marrink SJ, Risselada HJ, Yefimov S, Tieleman DP, de Vries AH. The MARTINI force field: coarse grained model for biomolecular simulations. J Phys Chem B. 2007;111(27):7812-24

21. Jo S, Kim T, lyer VG, Im W. CHARMM-GUI: a web-based graphical user interface for CHARMM. J Comput Chem. 2008;29(11):1859-65.

22. Periole X, Cavalli M, Marrink SJ, Ceruso MA. Combining an elastic network with a coarse-grained molecular force field: structure, dynamics, and intermolecular recognition. J Chem Theory Comput. 2009:5(9):2531-43.

23. Abraham MJ, Murtola T, Schulz R, Páll S, Smith JC, Hess B, Lindahl E. GROMACS: high performance molecular simulations through multi-level parallelism from laptops to supercomputers. SoftwareX. 2015;1-2:19-25.

24. Wassenaar TA, Pluhackova K, Bockmann RA, Marrink SJ, Tieleman DP. Going backward: a flexible geometric approach to reverse transformation from coarse grained to atomistic models. J Chem Theory Comput. 2014;10(2):676-90

25. Schrodinger LLC. The PyMOL molecular graphics system, version 1.8; 2015.

26. Clarke P, Mann J, Simpson JF, Rickard-Dickson K, Primus FJ. Mice transgenic for human carcinoembryonic antigen as a model for immunotherapy. Cancer Res. 1998;58(7):1469-77.

27. Li L, Bading J, Yazaki PJ, Ahuja AH, Crow D, Colcher D, Williams LE, Wong JY, Raubitschek A, Shively JE. A versatile bifunctional chelate for radiolabeling humanized anti-CEA antibody with In-111 and Cu-64 at either thiol or amino groups: PET imaging of CEA-positive tumors with whole antibodies. Bioconjug Chem. 2008;19(1):89-96.

28. Weidle UH, Kontermann RE, Brinkmann U. Tumor-antigen-binding bispecific antibodies for cancer treatment. Semin Oncol. 2014;41(5):653-60.

29. Dillon M, Yin Y, Zhou J, McCarty L, Ellerman D, Slaga D, Junttila $\Pi$, Han G, Sandoval W, Ovacik MA, et al. Efficient production of bispecific IgG of different isotypes and species of origin in single mammalian cells. MAbs. 2017;9(2):213-30. 
30. Brinkmann U, Kontermann RE. The making of bispecific antibodies. MAbs. 2017;9(2):182-212.

31. Hammarstrom S. The carcinoembryonic antigen (CEA) family: structures, suggested functions and expression in normal and malignant tissues. Semin Cancer Biol. 1999;9(2):67-81.

32. Osada T, Patel SP, Hammond SA, Osada K, Morse MA, Lyerly HK. CEA/CD3bispecific T cell-engaging (BiTE) antibody-mediated T lymphocyte cytotoxicity maximized by inhibition of both PD1 and PD-L1. Cancer Immunol Immunother. 2015;64(6):677-88.

33. Oberst MD, Fuhrmann S, Mulgrew K, Amann M, Cheng L, Lutterbuese $P$, Richman L, Coats S, Baeuerle PA, Hammond SA. CEA/CD3 bispecific antibody MEDI-565/AMG 211 activation of T cells and subsequent killing of human tumors is independent of mutations commonly found in colorectal adenocarcinomas. MAbs. 2014;66(6):1571-84.

34. Herve P, Flesch M, Cahn JY, Racadot E, Plouvier E, Lamy B, Rozenbaum A Noir A, Des Floris RL, Peters A. Removal of marrow T cells with OKT3-OKT11 monoclonal antibodies and complement to prevent acute graft-versus-host disease. A pilot study in ten patients. Transplantation. 1985;39(2):138-43.

35. Ridgway JB, Presta LG, Carter P. 'Knobs-into-holes' engineering of antibody $\mathrm{CH} 3$ domains for heavy chain heterodimerization. Protein Eng. 1996;9(7):617-21.

36. Spiess C, Zhai Q, Carter PJ. Alternative molecular formats and therapeutic applications for bispecific antibodies. Mol Immunol. 2015;67(2 Pt A):95-106.

37. Labrijn AF, Meesters Jl, de Goeij BE, van den Bremer ET, Neijssen J, van Kampen MD, Strumane K, Verploegen S, Kundu A, Gramer MJ, et al. Efficient generation of stable bispecific lgG1 by controlled Fab-arm exchange. Proc Natl Acad Sci U S A. 2013;110(13):5145-50

38. Patterson JT, Gros E, Zhou H, Atassi G, Kerwin L, Carmody L, Zhu T, Jones B, Fu Y, Kaufmann GF. Chemically generated IgG2 bispecific antibodies through disulfide bridging. Bioorg Med Chem Lett. 2017;27(16):3647-52.

\section{Publisher's Note}

Springer Nature remains neutral with regard to jurisdictional claims in published maps and institutional affiliations.

Ready to submit your research? Choose BMC and benefit from:

- fast, convenient online submission

- thorough peer review by experienced researchers in your field

- rapid publication on acceptance

- support for research data, including large and complex data types

- gold Open Access which fosters wider collaboration and increased citations

- maximum visibility for your research: over $100 \mathrm{M}$ website views per year

At $\mathrm{BMC}$, research is always in progress.

Learn more biomedcentral.com/submissions 